\title{
PLANEJAMENTO DO TURISMO PARA O DESENVOLVIMENTO LOCAL
}

\author{
TOURISM PLANNING FOR LOCAL DEVELOPMENT
}

\author{
Marina Duarte Gomes Silva ${ }^{1}$ \\ Elis de Araújo Miranda ${ }^{2}$
}

\section{RESUMO}

Este artigo aborda como o planejamento da atividade turística pode contribuir para o desenvolvimento local, e foi elaborado a partir de uma pesquisa bibliográfica que subsidiou teoricamente as análises do lazer, turismo, planejamento turístico e desenvolvimento local. Com base nos estudos acadêmicos que serviram para nortear esta pesquisa, identificou-se como o turismo está associado ao desenvolvimento do território, e como esse desenvolvimento, primeiramente, deve atender ao bem-estar da população residente, para depois estar adequado para o visitante usufruir do local turístico. Apontou-se como o benefício econômico dessa atividade contribuiu para a inserção do setor nas agendas políticas locais, com elaboração de ações específicas. Buscou-se analisar o planejamento integrado do turismo a diferentes atividades econômicas e sociais. Apontou-se também a importância dos planos setoriais nacionais, regionais e locais estarem conectados para um desenvolvimento adequado do território. Como resultado, observa-se a necessidade de uma educação turística para órgãos públicos, empresários locais e população residente, além da necessidade de um processo participativo da comunidade na elaboração das diretrizes para o aprimoramento do turismo. Dessa maneira, o desenvolvimento local a partir dessa atividade pode alcançar, além da sua finalidade econômica, como o envolvimento de empresas locais, benefícios sociais para as comunidades envolvidas, que terão preservadas suas manifestações culturais, história e meio ecológico local.

Palavras-chave: Lazer; Turismo; Planejamento e desenvolvimento local.

\section{ABSTRACT}

This article addresses how the touristic activity planning can contribute to the local development. For the elaboration of this study it was performed a bibliographic research that subsidized theoretically the analysis of leisure, tourism, touristic planning and local development. From academic studies that served to guide this research, it was identified how the tourism is associated to the territory development, and how this development, first, should attend the welfare of the resident population, to after be proper for the visitant enjoy the touristic local. It was pointed out how the economic benefit of this activity contributed for the insertion of the sector in the local policies agenda, with elaboration of specific actions. We aimed analyze the planning integrated of the tourism to different economic and social activities. It was also highlighted the importance of the sectoral, national, regional and local plans being connected for a proper development of the territory. As result, it is observed the need of a touristic education for public organs, local business and resident population. And, associated to that, the need of a community participatory process preparing the guidelines for the improvement of tourism. This way, the local development, from this activity, can reach, beyond your economic purpose as the local companies' involvement, social benefits for the involved communities, preserving your culture and history.

\footnotetext{
${ }^{1}$ Mestre em Planejamento Regional e Gestão de Cidades pela Universidade Candido Mendes - Campos dos Goytacazes (2012). Professora do Instituto Federal de Educação, Ciência e Tecnologia Fluminense (IFF).

2 Doutora em Planejamento Urbano e Regional pela Universidade Federal do Rio de Janeiro (UFRJ) (2006). Professora Adjunto II, Universidade Federal Fluminense (UFF), Polo Universitário de Campos dos Goytacazes, Departamento de Geografia.
} 
Keywords: Leisure; Tourism; Planning and local development.

\section{Introdução}

O desenvolvimento do turismo tem sido alvo dos poderes públicos municipais que buscam os ganhos econômicos da atividade, como o aumento de renda da população e do produto interno e redistribuição de renda (ACARENZA, 2002). Porém, para que o turismo possa contribuir para melhores condições socioeconômicas das populações locais, é necessário um planejamento adequado da atividade turística por parte da gestão local.

O planejamento do turismo e do lazer deve estar associado a ações de desenvolvimento territorial como um todo, caso contrário, o crescimento da atividade acarretará mais impactos negativos no território do que propriamente um desenvolvimento local. Esse planejamento interdisciplinar pressupõe ações coordenadas de diferentes setores da administração pública (SOUZA, 2011).

Os últimos planos setoriais brasileiros conduzem no seu discurso a interiorização do desenvolvimento turístico, com isso houve o aumento de estratégias para o desenvolvimento do turismo em locais que, até então, não possuíam qualquer orientação para propagar essa atividade. Em municípios pequenos, que possuem uma economia baseada no setor de serviços, o desenvolvimento do turismo por meio do crescimento do fluxo de visitantes regionais representa um potencial que deve ser avaliado pela administração pública de turismo e lazer local.

O objetivo deste trabalho consiste em abordar temas pertinentes ao desenvolvimento local a partir da atividade turística e, ainda, como as ações de planejamento do turismo podem assegurar o desenvolvimento adequado do setor. $\mathrm{O}$ presente artigo possui, primeiramente, uma apresentação do tema, do objetivo e da metodologia adotada. E segue com as identificações dos aspectos teóricos do planejamento do turismo e a importância de associálos ao desenvolvimento local, prevendo o respeito ao patrimônio natural, cultural e continuidade das atividades turísticas propulsoras de desenvolvimento e não associadas a transtornos e visitas indesejadas.

Procurando atender aos objetivos, foram realizadas pesquisas bibliográficas em livros, publicações e periódicos, com a finalidade de construir a fundamentação teórica desse estudo, autores como Cruz (2000), Yázigi (2009), Marcelino (2007) e Beni (2000) nos orientaram para encontrar as definições de turismo, lazer e planejamento do turismo. O referencial teórico dessa pesquisa encontra-se baseado no entendimento de que "a organização do território é fundamental para o desenvolvimento do turismo e indispensável para o habitante comum" (YÁZIGI, 2009, p. 32) e visando esse cenário, a administração pública deve deferir o planejamento da atividade.

\section{Lazer, turismo e planejamento turístico}

O turismo é ao mesmo tempo uma atividade humana diretamente relacionada ao lazer e também um setor que pode contribuir para o alcance de metas no campo econômico, no desenvolvimento cultural, para as práticas esportivas e para a valorização do meio ecológico. $\mathrm{Na}$ sociedade contemporânea, o lazer representa as atividades que podem ser desenvolvidas 
buscando o entretenimento, o descanso e o desenvolvimento pessoal e social (MARCELLINO, 2007).

Dumazedier (1980, p. 51) destaca o lazer como:

Um conjunto de ocupações às quais o indivíduo pode entregar-se de livre vontade, seja para repousar, seja para divertir-se, recrear-se e entreter-se ou, ainda, para desenvolver sua informação ou formação desinteressada, sua livre capacidade criadora, após livrar-se ou desembaraçar-se das obrigações profissionais, familiares e sociais.

Os processos de urbanização, industrialização e os recursos da comunicação de massa contribuíram para que o crescimento do lazer estivesse associado à qualidade de vida da população (BACAL, 2003). Com a crescente industrialização, os espaços urbanos começaram a ser ocupados por construções - casas, prédios, comércios, indústrias - para atender a uma parcela da população que foi atraída para as cidades, buscando condições diferentes de vida daquelas que possuíam nos ambientes rurais. Nesse processo de urbanização, as cidades eram os espaços mais acessíveis para a realização de atividades de lazer para a maioria da população (MARCELINO, 2007). Porém, contraditoriamente, o crescimento urbano gerou um esvaziamento dos espaços públicos de lazer, seja pela necessidade do mercado imobiliário de ocupação dos espaços para a construção de imóveis ou mesmo pela falta de segurança pública.

Na sociedade moderna capitalista, a concepção do lazer está relacionada ao consumo de bens e serviços, aspecto esse intensificado pelo trabalho dos meios de comunicação de massa que atuam na propagação de ideias que associam o lazer às atividades de consumo e não ao desenvolvimento pessoal: "o tempo livre torna-se um tempo social e o lazer torna-se um produto da sociedade de consumo, mercadoria que se vende e se compra" (RODRIGUES, 1997 p. 109 apud PORTUGUEZ, 2001, p. 10). As mensagens publicitárias, por exemplo, de venda de paisagens naturais exuberantes e de hotéis com diversos equipamentos de lazer disponíveis valorizam o lazer apenas pela sua capacidade de propiciar a felicidade e bem-estar físico e psicológico (BACAL, 2003).

O consumo do lazer e do turismo se torna mais um método de inserção no grupo social no qual se está inserido, é símbolo de status, "é uma terapia da sociedade, como válvula que faz manter o funcionamento do mundo de todos os dias" (KRIPPENDORF, 2000, p. 16). Destaca-se, então, que o direito ao lazer e o uso do tempo para essa atividade recai - assim como o acesso a moradia, educação, saúde, trabalho, segurança - na questão da exclusão social e da segregação do território. Para uma parcela da população, o lazer se resume em atividades realizadas dentro da moradia, como a televisão, que viabiliza com a facilidade [e passividade] o entretenimento para aqueles que não podem consumir o lazer vendido pelas publicidades anunciadas e que toleram a ausência dos espaços públicos e equipamentos de lazer não oferecidos nos centros urbanos. Assim, o enfrentamento dessa exclusão, causada pela busca da aceitação social e pelo consumo do lazer e do turismo, será efetivado por políticas econômicas e sociais associada ao "resgate dos valores culturais, da ética nas relações cotidianas e de estímulo às soluções encontradas pelos pobres, para sua sobrevivência” (RIBEIRO, 1996, p. 62 apud RODRIGUES, 1999, p. 62).

Diante desse cenário, o planejamento do lazer deve atender e garantir o acesso aos espaços públicos, bem como propiciar alternativas de lazer a toda comunidade: 
No momento em que nós fizermos com que este Estado entenda que ele tem que ter uma política de bem-estar social, que além da comida, que é essencial, do trabalho, que é essencial, da casa, enfim do be-a-bá da vida contemporânea, que ele precisa alongar-se numa dimensão do lazer que seja criatividade e liberdade, nós teremos completado a nossa tarefa de transição democrática, de formação de um Estado realmente moderno [...] (CARDOSO, 1986 apud OLIVEIRA, 2000, p. 54).

Nessa sociedade urbana, onde o lazer é comercializado e consumido com o intuito de entretenimento, descanso e fuga do tempo de trabalho, ele mantém uma estreita relação com o turismo. Esses dois campos têm sido valorizados e consequentemente se tornaram alvos do planejamento público, mesmo que a gestão dessas atividades ainda careça de maior cuidado. As ações visando ao desenvolvimento desses dois fenômenos devem ser compreendidas de uma maneira associada, ou seja, os equipamentos e serviços de lazer de uma cidade só serão motivos de atração de turistas se atenderem antes a comunidade local.

A partir do uso do tempo do não trabalho, institui-se uma nova atividade, o turismo "que se constitui apenas uma forma de mobilidade temporária orientada para o lazer" (LEW; HALL; WILLIAMS, 2004, p. 26). O turismo é considerado um fenômeno econômico, social e cultural. Moesch (2002) utiliza da relação entre esses elementos para definir o turismo:

Turismo é uma combinação complexa de inter-relacionamentos entre produção e serviços, em cuja composição interam-se uma prática social com base cultural, com herança histórica, a um meio ambiental diverso, cartografia natural, relações sociais de hospitalidade, troca de informações interculturais. O somatório desta dinâmica sociocultural gera um fenômeno, recheado de objetividade/subjetividade, consumido por milhões de pessoas, como síntese: o produto turístico (MOESCH, 2002, p. 9).

A prática do turismo envolve o consumo de serviços relativos às práticas de lazer, ao alojamento, ao transporte, a alimentos e bebidas, assim como consumo de bens culturais e a participação em eventos: "a soma dos fenômenos e das relações resultantes da viagem e da permanência de não-residentes, na medida em que não leva à residência permanente e não está relacionada a nenhuma atividade remuneratória" (HUNZIKER; KRAPF apud BENI, 2008, p. 36).

A partir do início do século XIX, com o surgimento do termo turismo, e na medida em que essa prática registra sua importância socioeconômica e cultural no desenvolvimento dos países, o turismo tem sido fenômeno estudado por diferentes áreas de conhecimento:

[...] e pode-se afirmar que a partir daí foi possível distinguir e agrupar um conjunto de atividades que antes do uso desse termo eram conhecidas por outros nomes. Viagens realizadas por motivos religiosos, terapêuticos, culturais, esportivos ou para participação em feiras existiam há muito tempo, e seus desdobramentos econômicos já eram conhecidos desde a Antiguidade pelos gregos e romanos, e mesmo durante toda a Idade Média. Mas, somente 
com a criação do termo, e o surgimento da atividade turística propriamente dita, cujo marco é a viagem articulada por Thomas Cook, em 1841, é que um conjunto significativo de fenômenos sociais passaram a ser englobados sob uma mesma palavra - turismo (DIAS, 2003, p. 12).

A participação dessa atividade na economia e sociedade brasileira vem crescendo à medida que registra sua importância no desenvolvimento territorial como instrumento de geração de divisa, responsável por investimentos em outros segmentos produtivos que possibilitam a geração de emprego e renda e sua crescente participação no Produto Interno Bruto (UMBELINO; SILVA, 2010).

Cruz (2000) enfatiza que a atividade se utiliza de parte do espaço geográfico e o consumo dos territórios pelo turismo é intermediado por inúmeras formas representadas pelo uso de hotéis e pousadas, meios de transporte, estabelecimentos de alimentos e bebidas e pelo uso de equipamentos de lazer. Segundo a autora, essa amplitude do turismo é a razão que o torna capaz de reorganizar o território.

Essa estreita relação da atividade turística com o território é explicada por Dias (2008, p. 37): "o território é um elemento básico do desenvolvimento turístico, pois abriga os recursos ambientais e culturais", além de ser o espaço em que infraestrutura e equipamentos se instalam para o uso dos visitantes. O turismo se apropria desses espaços, reordenando territórios e gerando modificações na vida das pessoas e nos locais em que elas vivem (HALL, 2001), e esses impactos muitas vezes não serão positivos para a população e para o futuro da atividade naquela localidade:

[...] É contundente a manifestação de autores (ARRONES, 1992; URRY, 2000; KRIPEENDORF, 2003) alertando para o caráter depredador e colonizador do turismo, uma atividade insustentável, autofágica, que destrói as culturas dos povos e as reservas ambientais (TOMAZZONI, 2009, p.14).

A saturação de meios de transporte e da infraestrutura básica, as modificações culturais e prejuízos ambientais são exemplos de problemas que podem ocorrer no desenvolvimento do turismo sem planejamento. Becker (2002) caracteriza o turismo como uma atividade híbrida que tanto pode trazer desenvolvimento socioeconômico como tem potencial para a degradação ambiental e social e que esses impactos podem ser evitados, algumas vezes, com uma regulação para o setor.

Hall (2001 p.17) completa que, "para cada notícia de sucesso, parece haver outras dez de fracasso ou, pelo menos, um maior reconhecimento do impacto negativo exercido pelo turismo". O turismo tem o potencial de facilitar o desenvolvimento socioeconômico de um local, mas para isso, antes de atender às necessidades dos turistas, a organização do território deve atender ao cotidiano da comunidade local e respeitar o direito a um ambiente público de lazer (YÁGIZI, 2009).

Atualmente, em consequência dos números já apresentados pela atividade na economia, o turismo despertou o interesse de gestores locais que não possuem produto turístico consolidado. Áreas com falta de infraestrutura turística e atrações competitivas "olham avidamente para o turismo como caminho para diversificação" (RIBEIRO; MARQUES, 2001 apud CHURCH, 2004, p. 621). 
Contudo, as iniciativas podem representar benefícios às economias se o turismo for desenvolvido através de um planejamento da atividade em âmbito nacional, estadual e municipal e gerido de uma maneira a minimizar os possíveis impactos negativos.

\section{O turismo como política de estado}

No atual panorama de crescimento do turismo, o planejamento da atividade, além de visar ao desenvolvimento econômico, se tornou um instrumento para a conservação dos recursos naturais, culturais, históricos e sociais. Muito embora "o planejamento não seja uma panaceia para todos os males" (HALL, 2001, p. 29), esse processo pode minimizar impactos negativos e maximizar retornos econômicos:

[...] Na realidade, a função do planejamento é nortear o crescimento turístico de modo a compatibilizar os fatores econômicos com os fatores de ordem social e ambiental, determinando metas e objetivos precisos e disponibilizando os meios próprios para os atingir (SILVEIRA, 2003).

O planejamento pode ser um instrumento de desenvolvimento que orienta para um determinado futuro escolhido previamente (DIAS, 2003). Para Krippendorf (2000), uma das finalidades do planejamento turístico é estabelecer políticas públicas para o desenvolvimento da atividade, além de atender a objetivos gerais socioeconômicos, culturais e ecológicos da localidade.

Planejar e desenvolver os espaços e as atividades que atendam aos anseios das populações locais e dos turistas constitui a meta dos poderes públicos que, para implantá-las, vêem - se diante de dois objetivos conflitantes: o primeiro, que é o de prover oportunidade e acesso às experiências recreacionais ao maior número de pessoas possível, contrapões-se ao segundo, de proteger e evitar a descaracterização dos locais privilegiados pela natureza e do patrimônio cultural das comunidades (RUSCHAMANN, 1997, p. 87).

Contudo, para que esses objetivos sejam alcançados, é necessário que a comunidade de um dado destino esteja envolvida nas etapas do planejamento setorial e que esse processo esteja relacionado com diferentes atividades locais e que se estabeleça não apenas um planejamento comercial do turismo.

\section{Planejamento integrado para o desenvolvimento local}

O turismo é uma atividade que não depende exclusivamente de atrativos que remetem aos meio ecológicos ou histórico-culturais para existir em um dado local. Entende-se que o termo "meio ecológico" é o melhor para nomear os espaços ditos naturais e seus correspondentes turísticos, os atrativos naturais. Santos (1985, p. 8) define que essa expressão: 
não tem a mesma significação dada à natureza selvagem ou natureza cósmica, como às vezes se tende a admitir. $\mathrm{O}$ meio ecológico já é o meio modificado e cada vez mais técnico [...], logo não tem o mesmo significado de natureza selvagem e, sim, de meio ecológico modificado, visto a incidência cada vez mais constantes dos objetos geográficos que lhe concedem uma nova configuração socioespacial.

As estruturas básicas e turísticas também são necessárias para que a atividade possua continuidade e não prejudique a comunidade local:

Se uma cidade tem que possuir toda infraestrutura indispensável a vida, com muito mais forte razão, o lugar turístico deve não só suprir suas necessidades, como ainda dispor de reservas para atender a sazonalidade. Não basta que serviços públicos existam: é preciso que sejam de qualidade (YÁZIGI, 2009, p. 90).

A atividade turística se utiliza de infraestrutura básica para seu crescimento, assim como a existência de uma estrada de boa qualidade, redes elétricas e de comunicação eficientes, a existência de um sistema de coleta de lixo e esgoto, que facilitam o aumento do fluxo de visitantes em um local de interesse. Para que o planejamento do turismo seja eficiente, é necessário que existam políticas públicas de saneamento, saúde, transporte, meio ambiente entre outras (BARRETO; BURGOS; FRENKEL 2003). Além disso, a infraestrutura turística - como bares e restaurantes, serviços de entretenimento, hotéis e pousadas e sistema de transporte intrarregional - é necessária para impulsionar o crescimento de um local turístico.

Com essa característica, de articulação com outros segmentos, torna-se necessário um planejamento turístico integrado com diferentes setores privados e da administração pública, seja ela nacional, estadual ou municipal. Essa integração é fundamental para que haja um "desenvolvimento consequente", e Yázigi (2009, p. 52) alerta que "uma integração suficiente e profunda requer interação entre todos os setores de governo e da sociedade que se mostrarem necessários, regulados por normas institucionais e duradouras".

O desenvolvimento do turismo sem o planejamento integrado a outros setores pode acarretar modificações negativas no território, tanto para a população local quanto para os turistas que o visitam. No caso do espaço urbano, o uso e ocupação do solo para fins turísticos sem controle público podem sobrecarregar a infraestrutura básica, deteriorar o espaço público e, inevitavelmente, esse local perde sua atratividade pela descaracterização e mau uso dos recursos urbanos (infraestrutura e equipamentos). A valorização imobiliária provocada pelo turismo em alguns locais pode, em casos mais graves, deflagrar uma ocupação irregular em áreas de preservação ambiental por condomínios e/ou hotéis; ou mesmo inflacionar os preços dos imóveis em espaços urbanos favoráveis à atividade turística, como áreas próximas das praias nas cidades brasileiras.

A falta de planejamento integrado pode vir a prejudicar o interesse turístico de certa localidade, a interação entre todos os setores de governo no planejamento evita novos casos brasileiros de lugares turísticos que passaram por favelização, mercantilização, descaracterização e descuidos dos espaços (YÁZIGI, 2009).

Os problemas de disparidade socioeconômica de regiões brasileiras não serão resolvidos por "soluções de varejo" (YÁZIGI, 1998 apud CRUZ, 2000, p. 64). Um dado setor não será capaz de fomentar sozinho o desenvolvimento de um local. Nem mesmo o turismo, 
que se baseia em estatísticas favoráveis às quais expressam a importância da atividade na economia nacional, estadual ou municipal, terá seu espaço assegurado no desenvolvimento de uma região se não estiver associado ao planejamento do território como um todo.

O desenvolvimento local, segundo Coriolano (2012), é aquele realizado de forma participativa, que atende às necessidades de trabalhadores de um lugar, com valorização de pequenas empresas locais e das características históricas, culturais e ambientais dos lugares. A participação social no processo de planejamento é de fundamental importância nesse processo de desenvolvimento do turismo no território. Para Hall (2001, p. 55), um planejamento que possua essa participação pode assegurar um "desenvolvimento na comunidade e não da comunidade".

Existe uma necessidade de um planejamento combinado com uma educação turística da comunidade local para que ela assimile a importância da atividade turística. Além disso, a educação dos órgãos municipais de turismo é fundamental:

A aspiração turística de muitos lugares vem se avolumando, numa aberta tentativa de aumentar os rendimentos econômicos [...]. Prefeituras têm que ser educadas para o turismo, especialmente onde ele se contenta com pedalinhos e outras fragilidades (YÁZIGI, 2009, p. 493).

Dessa maneira, para que esse processo de desenvolvimento local a partir do turismo siga um percurso de respeito ao ambiente natural, aos aspectos culturais e sociais e não apenas vislumbrando os lucros que o turismo possa gerar, as ações de planejamento devem possuir estratégias para promover retorno para a comunidade.

\section{Considerações finais}

$\mathrm{O}$ crescimento do turismo nacional e internacional ocasionou nas últimas décadas uma evolução do planejamento e das políticas públicas do setor. Muitos municípios brasileiros buscam desenvolver a atividade turística no seu território a fim de obter ganhos econômicos. Porém, tão importante quanto os benefícios financeiros, é a capacidade que o segmento tem de promover o desenvolvimento local, a partir da valorização a cultura, da preservação do meio ecológico e promovendo o retorno para a comunidade.

Destarte, para que a atividade alcance esses níveis desejáveis, é fundamental um planejamento para o desenvolvimento ordenado do setor e uma gestão eficiente das ações de promoção e manutenção da atividade. Esse processo deve ocorrer de forma horizontal nas diferentes políticas setoriais nacionais, estaduais e locais. Uma política social, de transporte, de educação, de meio ambiente deve estar associada sempre com a política turística, uma vez que esse setor se apropria dos espaços para o seu desenvolvimento.

Portanto, a administração local deve estar atenta para que o processo de planejamento turístico esteja associado antes de tudo, às necessidades e aos desejos da população residente. Utilizando-se da argumentação de Figueiredo (2008), é necessário que os responsáveis por esse processo entendam que os espaços públicos são vistos como pontos de referencia cultural e entretenimento por visitantes, mas antes disso, esses espaços possuem a função de proporcionar lazer aos moradores.

Dessa maneira, a educação turística dos órgãos municipais, associações do setor e empresários locais se torna instrumento necessário para que, paralelamente a isso, a 
elaboração de planos municipais de desenvolvimento turístico faça parte de um processo participativo, assim sendo, a ampliação do turismo no território não será mais um elemento de exclusão de uma parcela dos residentes locais.

\section{REFERÊNCIAS}

ACARENZA, Miguel Angel. O turismo e o desenvolvimento nacional. In: Administração do Turismo. Bauru: EDUSC, 2002. p. 153-186.

BACAL, Sarah. Lazer e o universo dos possíveis. São Paulo: Aleph, 2003. 144 p.

BARRETO, Margarita; BURGOS, Raul; FRENKEL, David. Turismo, políticas e relações internacionais. Campinas: Papirus, 2003. 128 p.

BECKER, Bertha. Políticas e planejamento do turismo. In: YÁZIGI, Eduardo; CARLOS, Ana Fani Alessandri; CRUZ, Rita de Cássia A. da. Turismo: espaço, paisagem e cultura. 3. ed. São Paulo: 2002. p. 181-192.

BENI, Mário Carlos. Política e estratégia do desenvolvimento regional: planejamento integrado e sustentável do turismo. In: LAGE, Beatriz Helena Gelas; MILONE, Paulo Cesar. Turismo: teoria e prática. São Paulo: Atlas, 2000. p. 165-171.

BENI, Mário Carlos. Análise estrutural do turismo. São Paulo: Senac, 2008. 560 p.

CHURCH, A. Políticas de turismo local e regional e o poder. In: LEW, Alan A.; HALL, C. Michael; WILliAMS, Allan M. Compêndio de Turismo. Lisboa: Instituto Piaget, 2004. p. 617- 630 .

CORIOLANO, Luzia Neide. A contribuição do turismo ao desenvolvimento local. In: PORTUGUEZ, Anderson Pereira; SEABRA, Giovanni de Farias; QUEIROZ, Odaléia Telles Marcondes Machado. Turismo, espaço e estratégias de desenvolvimento local. João Pessoa: Editora Universitária da UFPB, 2012. p. 61-70.

CRUZ, Rita de Cássia Ariza da. Política de Turismo e Território. São Paulo: Contexto, 2000. 167 p.

DIAS, Reinaldo. Sociologia do Turismo. São Paulo: Atlas, 2003. 245 p.

DIAS, Reinaldo. Planejamento do Turismo: política e desenvolvimento do turismo no Brasil. São Paulo: Atlas, 2008. 226 p.

DUMAZEDIER, Joffre. Valores e conteúdos culturais do lazer. Tradução Regina Maria Vieira. São Paulo: SESC, 1980. 176 p.

FIGUEIREDO, Silvio Lima. Espaços públicos nas cidades: notas sobre o ordenamento, acessibilidade e turistificação. In: regional. Belém: NAEA, 2008. p. 79-92. . Turismo, lazer e planejamento urbano e

HALL, Colin Michael. Política e planejamento turístico: o imperativo sustentável. In:

Planejamento turístico: políticas, processos e relacionamentos. São Paulo: Contexto, 2001. p. 17-36. 
KRIPPENDORF, Jost. Sociologia do turismo: para uma nova compreensão do lazer e das viagens. São Paulo: Aleph, 2000. 186 p.

LEW, Alan A.; HALL, C. Michael; WILLIAMS, Allan M. Turismo: conceitos, instituições e temas. In: Compêndio de Turismo. Lisboa: Instituto Piaget, 2004. p. 23-41.

MARCELLINO, Nelson Carvalho et al. Lazer, cultura e patrimônio ambiental urbano políticas públicas: o caso de Campinas e Piracicaba- SP. Curitiba: OPUS, 2007. 177 p.

MOESCH, Marutschka Martini. A produção do saber turístico. São Paulo: Contexto, 2002. $144 \mathrm{p}$.

OLIVEIRA, Paulo de Salles. Trabalho, não-trabalho e contradições sociais. In: BRUHNS, Heloisa Turini (Org.). Temas sobre o lazer. Campinas: Autores Associados, 2000. p. 47-63.

PORTUGUEZ, Anderson Pereira. Consumo e espaço: turismo, lazer e outros temas. São Paulo: Roca, 2001. cap. 1, p. 3-30.

RODRIGUES, Adyr Balastreri. Turismo local: oportunidades para inserção. In:

Turismo e desenvolvimento local. São Paulo: Hucitec, 1999. p. 55-64.

RUSCHMANN, Doris van de Meene. Turismo e planejamento sustentável. São Paulo: Papirus, 1997. $200 \mathrm{p}$.

SANTOS, Milton. Espaço e Método. São Paulo: EDUSP, 1985. 120 p.

SILVEIRA, Marcos Aurélio Tarlombani da. Turismo, Políticas de Ordenamento Territorial e Desenvolvimento. Um foco no Estado do Paraná no Contexto Regional. In: ENCONTRO DE GEÓGRAFOS DA AMÉRICA LATINA, 9, 2003, México. Anais... Disponível em: <http://www.observatoriogeograficoamericalatina.org.mx/egal9/Geografiasocioeconomica/Ge ografiaturistica/06.pdf>. Acesso em: 10 jan. 2014.

SOUZA, Marcelo Lopes de. Planejamento e gestão urbanos como ferramentas de promoção do desenvolvimento sócio-espacial. In: Mudar a cidade: uma introdução crítica ao planejamento e a gestão urbanos. 8. ed. Rio de Janeiro: Bertrand Brasil, 2011. p. 60-82.

TOMAZZONI, Edegar Luis. Desenvolvimento econômico e regionalidade. In:

Turismo e desenvolvimento regional: dimensões, elementos e indicadores. Caxias $\overline{\text { do Sul: }}$ Educs, 2009. p. 17-74.

UMBELINO, Luis Felipe; SILVA, Marina Duarte Gomes. Um panorama da atividade turística na região Noroeste Fluminense. In: MARAFON, Gláucio Jose; RIBEIRO, Miguel Angelo. Revisitando o Território Fluminense III. Rio de Janeiro: Gramma, 2010. p. 65-75.

YÁZIGI, Eduardo. Saudades do futuro: por uma teoria do planejamento territorial do turismo. São Paulo: Plêiade, 2009. 573 p. 